\title{
ТЕОРЕТИЧНЕ ВИЗНАЧЕННЯ ХАРАКТЕРИСТИК НАПРУЖЕНО- ДЕФОРМОВАНОГО СТАНУ ТА НЕСУЧОЇ ЗДАТНОСТІ НОРМАЛЬНИХ ПЕРЕРІЗІВ КОМБІНОВАНО-АРМОВАНИХ ЗГИНАЛЬНИХ ЕЛЕМЕНТІВ
}

\section{THEORETICAL CALCULATION OF STRESS-STRAIN STATE CHARACTERISTICS AND BEARING CAPACITY OF NORMAL CROSS-SECTIONS OF COMBINED-REINFORCED SFRC BENDING ELEMENTS}

Андрійчук О.В., к.т.н., доц. (Луцький національний технічний університет), Нінічук М.В., технік I категорії (Луцький національний технічний університет)

Andriichuk O.V., Ph.D., associate professor, (Lutsk National Technical University), Ninichuk M.V., techn. of the I category (Lutsk National Technical University)

Запропоновано деформаційну методику розрахунку характеристик напружено-деформованого стану та несучої здатності комбіновано-армованих сталефібробетонних елементів із врахуванням повної роботи сталефібробетону на розтяг.

In recent years, the scope of application of reinforced concrete and combinedreinforced structures in load-bearing structures is expanding. Studies by many authors indicate the significant advantages of reinforced concrete and combined-reinforced bending elements over the classic reinforced concrete. Current state regulations do not take into account all the properties of reinforced concrete, and therefore the loadbearing capacity of structures can in many cases be underestimated. Therefore, it is advisable to take into account, when calculating, all the properties of this material.

The current state national standards for the calculation and design of fiber reinforced concrete structures are based on the fact that reinforced concrete is considered as one of the types of disperse-reinforced material. However, with this approach, many factors are taken into account, the value of which, in real conditions, can be in a wide range of values, so they are taken into account with a margin.

The article proposes an improved deformation method for calculating the stressstrain state characteristics and the bearing capacity of combined-reinforced concrete bending elements. Improved diagrams of deformation of reinforced concrete under compression and tensile obtained on the basis of experimental tests are taken into account. To evaluate the effectiveness of the method and study a number of other characteristics, two series of experimental studies of inseparable combined - reinforced reinforced concrete beams were performed. Research methods and the nature of the beams in the test process, described in [8-9]. For comparison with the obtained 
experimental data, the article presents the calculation of experimental beams, performed according to state standards and a simplified force method.

The proposed deformation method shows better convergence compared to the DSTU method. The average ratio of theoretical destructive bending moments to experimental is $k_{m}=0.98$ for the proposed deformation technique, $k_{m}=0.843$ for the method according to DSTU.

Ключові слова: бетон, сталева фібра, СФБ, розрахунок, деформачії, несуча здатність.

Keywords: concrete, steel fiber, SFRC, calculation, deformations, bearing capacity.

Постановка проблеми. Чинні норми проєктування сталефібробетонних конструкцій розглядають фіброву арматуру як дисперсну, і міцність на розтяг знаходять як добуток міцності фібри i коефіцієнтів орієнтації, зчеплення та ймовірності перетину фіброю розрахункової площини [1]. Такий підхід вимагає експериментального вивчення проблем зчеплення фібри з бетоном і експериментальнотеоретичного обгрунтування мінімального коефіцієнта фібрового армування. Також важливим $є$ врахування діаграм деформування, які б максимально відповідали дійсній роботі перерізів сталефібробетонних елементів. На даний час у ДСТУ - Н Б В.2.6 - 218:2016 [1] при розрахунку нормальних перерізів сталефібробетонних згинальних елементів, епюру напружень при стиску пропонується приймати параболічною згідно ДСТУ Б В.2.6-156 [2], а епюру за розтягу - дволінійною. За критерій вичерпання несучої здатності нормального перерізу сталефібробетонного елемента приймається досягнення крайніми розтягнутими волокнами значення деформацій рівних $\varepsilon_{f c t, u}=1,8 f_{c f t d} / E_{c d}$. Розрахунок за несучою здатністю сталефібробетонних елементів із комбінованим армуванням взагалі пропонується виконувати як для типових залізобетонних елементів згідно ДСТУ Б В.2.6-156 [2]. Однак чисельні дослідження роботи сталефібробетонних згинальних елементів вказують на значно більший діапазон роботи сталефібробетону за розтягу при згині $[3,4]$.

Аналіз відомих досліджень і публікацій. При дослідженні роботи згинальних сталефібробетонних елементів на фібрі із листа, вченим В.В. Білозіром для сталефібробетону на основі бетону-матриці, яка відповідає класу C25/30, були отримані значення деформацій розтягу $\varepsilon_{c t, l}=249 \ldots 278 \cdot 10^{-5}$ при максимальних напруження $f_{c t, u}=2,95 \ldots 3,06$ МПа. Коефіцієнт армування фіброю за об'ємом при цьому становив $\mu_{f v}=1,8 \%$ [5]. Автором пропонується для розрахунку комбіновано-армованих згинальних елементів використовувати діаграму деформування, в якій висхідна вітка за розтягу описується рівнянням параболи до рівня напружень, що відповідають тимчасовому опорові за розтягу $f_{c t}$, і лінійною функцією решта діаграми. Значення напружень при максимальних деформаціях $\varepsilon_{c t, u}=550 \cdot 10^{-5}$ приймаються рівними $\sigma_{c t, u}=0,37 f_{c t}$, а піковій точці діаграми відповідають деформації $\varepsilon_{c t, 1}=250 \cdot 10^{-5}$. 
Асоціацією RILEM пропонується для європейських норм прийняти ідеалізовану діаграму при розтягу трилінійною [6]. Висхідна вітка цієї діаграми продовжується горизонтальною прямою до деформацій, що рівні $\varepsilon_{c t, L l}=3,5 \cdot 10^{-3}$, а низхідна вітка закінчується при деформаціях $\varepsilon_{c t, u}=25 \cdot 10^{-3}$. Для комбіновано-армованих сталефібробетонних елементів граничні деформації сталефібробетону за розтягу прийняті рівними граничним деформаціям стержневої арматури.

Таким чином, існує низка пропозицій для опису ідеалізованих діаграм, прийнятність яких може бути оцінена лише експериментально.

Мета статті - удосконалити методику визначення параметрів напружено-деформованого стан нормальних перерізів комбінованоармованих сталефібробетонних згинальних елементів, із врахуванням повної роботи сталефібробетону на стиск і на розтяг.

У результаті власних експериментальних досліджень роботи сталефібробетонних призм на короткочасний осьовий розтяг [7], були встановлені наступні характеристики сталефібробетону: $f_{c t m}=2,35 \mathrm{MПа,}$ $\varepsilon_{c t, 1}=25 \cdot 10^{-5}$. Враховуючи ці дані, рекомендації RILEM та експериментальні дослідження роботи сталефібробетону на розтяг інших авторів, пропонується для розрахунку нормальних перерізів комбінованоармованих елементів епюру за розтягу приймати двохвіткову. Висхідна вітка описується параболою до рівня напружень $\sigma=f_{c t}$ при фіксованому значенні відносних деформацій $\varepsilon_{c t, l}=25 \cdot 10^{-5}$. Низхідну вітку діаграми пропонується описувати лінійною функцією до значення напружень, що рівні $\sigma_{c t, u}=0,25 f_{c t}$, гранична величина деформацій сталефібробетону при цьому приймається рівною граничним деформаціям стержневої арматури $\varepsilon_{c t, u}=25 \cdot 10^{-3}$ (рис. 1).

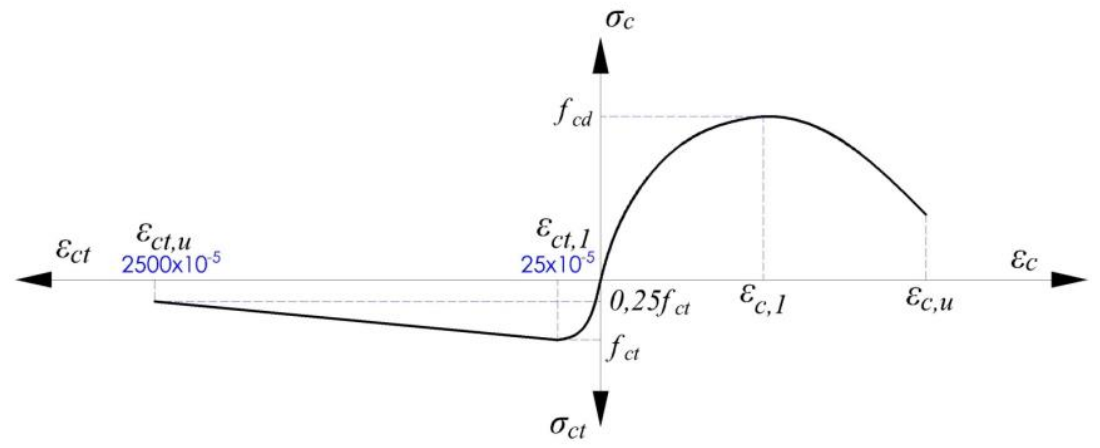

Рис. 1. Ідеалізована діаграма деформування сталефібробетону при розтягу, що пропонується в методиці 
Визначення параметрів напружено-деформованого стану нормальних перерізів комбіновано-армованих залізобетонних згинальних елементів виконується із урахуванням наступних передумов:

- для перерізів вважається справедливою гіпотеза про лінійний розподіл деформацій по висоті;

- деформації арматури та фібробетону, що іiі оточує, однакові при стиску і при розтягу;

- зв'язок між напруженнями та деформаціями стиснутого та розтягнутого сталефібробетону приймається у вигляді діаграм, які наведені на рис. 1 і рис. 2.

За критерій вичерпання несучої здатності перерізу, що обумовлює втрату рівноваги внутрішніх і зовнішніх сил, приймається досягнення максимального значення згинального моменту на діаграмі «момент кривизна» (екстремальний критерій).

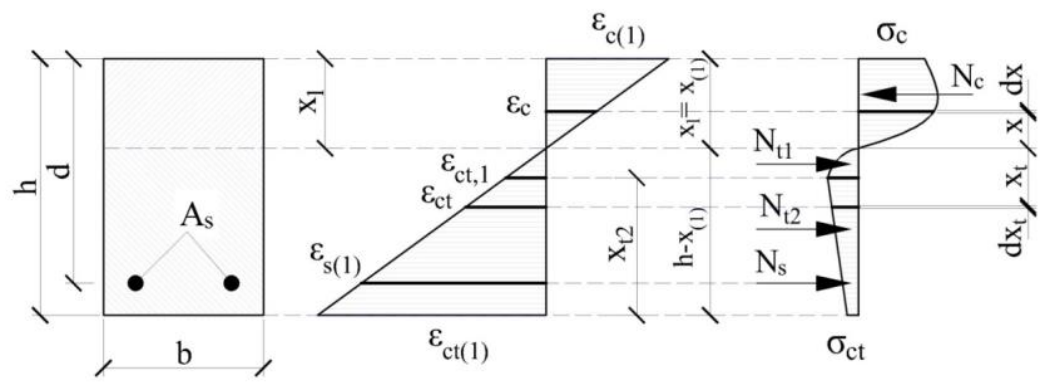

Рис. 2. Епюра деформацій і напружень поперечного перерізу згинальних елементів балкового типу

Залежність між напруженнями в сталефібробетні $\sigma_{c}$ і деформаціями $\varepsilon_{c}$ для короткотривалого осьового навантаження описується наступними рівняннями. Напруження при стискові:

$$
\sigma_{c}=f_{c d} \sum_{k=1}^{5} a_{k} \eta_{c}^{k}
$$

Напруження при розтягові на висхідній вітці:

$$
\sigma_{c t l}=f_{c t d} \sum_{k=1}^{5} a_{k} \eta_{t}^{k}
$$

Напруження при розтягові на низхідній вітці:

$$
\sigma_{c t 2}=f_{c t d}\left(1,525-210 \varepsilon_{c t}\right) \text {. }
$$

де $\eta_{c}=\frac{\varepsilon_{c}}{\varepsilon_{c, l}} ; \eta_{t}=\frac{\varepsilon_{c t}}{\varepsilon_{c t, l}} ; a_{k}-$ коефіцієнти полінома; 
Значення коефіцієнтів поліному $a_{k}$, як для стиснутої так і для розтягнутої вітки сталефібробетону визначаються згідно методики НДІБК [8]. Схема розподілу напружень і деформацій по висоті у перерізі згинального комбіновано-армованого елемента, що приймається в методиці зображено на рис. 2.

Для такого перерізу умова рівноваги записується у вигляді:

$$
M_{E d} \leq M_{S(1)}=M_{c(1)}+M_{s(1)}+M_{t 1(1)}+M_{t 2(1)} .
$$

Рівновага внутрішніх зусиль забезпечується виконанням умови:

$$
N_{c(1)}=N_{t 1(1)}+N_{t 2(1)}+N_{s(1)} .
$$

За гіпотезою плоских перерізів, при заданому значенні деформацій у стиснутій крайній фібрі бетоні $\varepsilon_{c}=\varepsilon_{c(1)}$, деформації у арматурі $\varepsilon_{s(l)}$ за фіксованого значення $x=x_{(1)}$ визначаються за формулами:

$$
\begin{gathered}
\varepsilon_{s(1)}=\frac{\varepsilon_{c(1)}}{x_{(1)}}\left(d-x_{(1)}\right) ; \\
\varepsilon_{c}=\frac{\varepsilon_{c(1)}}{x_{(1)}} x .
\end{gathered}
$$

За відомих деформацій в матеріалах внутрішні сили в стиснутому бетоні прямокутного перерізу знаходяться за формулою:

$$
N_{c(1)}=b \int_{0}^{x_{(1)}} \sigma_{c} d x=b \frac{x_{(1)}}{\varepsilon_{c(1)}} \int_{0}^{\varepsilon_{c(1)}} \sigma_{c} d \varepsilon_{c} .
$$

де $d x$ - висота елементарної площадки поперечного перерізу, а $x$ - віддаль від центра ваги елементарної площадки до нейтральної лінії. Враховуючи вираз (7), значення $x$ i $d x$ знаходяться за формулами:

$$
\begin{gathered}
x=\frac{x_{(1)}}{\varepsilon_{c(1)}} \varepsilon_{c} ; \\
d x=\frac{x_{(1)}}{\varepsilon_{c(1)}} d \varepsilon_{c} .
\end{gathered}
$$

Відповідно момент внутрішніх зусиль стиснутого бетону відносно нейтральної лінії знаходиться за формулою:

$$
M_{c(1)}=b \int_{0}^{x_{(1)}} \sigma_{c} x d x=b\left(\frac{x_{(1)}}{\varepsilon_{c(1)}}\right)^{2} \int_{0}^{\varepsilon_{c(1)}} \sigma_{c} \varepsilon_{c} d \varepsilon_{c} .
$$

Внутрішні зусилля в арматурі визначаються за формулами: 


$$
\begin{gathered}
N_{s(1)}=A_{s} \sigma_{s}=A_{s} E_{s} \varepsilon_{s(1)}=A_{s} E_{s} \frac{\varepsilon_{c(1)}}{x_{(1)}}\left(d-x_{(1)}\right) ; \\
M_{s(1)}=A_{s} E_{s} \frac{\varepsilon_{c(1)}}{x_{(1)}}\left(d-x_{(1)}\right)^{2} .
\end{gathered}
$$

Тоді значення внутрішніх зусиль для розтягнутого бетону на висхідній вітці можна записати як:

$$
\begin{gathered}
N_{t 1(1)}=b \int_{0}^{h-x_{(1)}} \sigma_{c t 1} d x_{t}=b \frac{h-x_{(1)}}{\varepsilon_{c t(1)}} \int_{0}^{\varepsilon_{c t(1)}} \sigma_{c t 1} d \varepsilon_{c t} \\
M_{t 1(1)}=b \int_{0}^{h-x_{(1)}} \sigma_{c t 1} x_{t} d x_{t}=b\left(\frac{h-x_{(1)}}{\varepsilon_{c t(1)}}\right)^{2} \int_{0}^{\varepsilon_{c t(1)}} \sigma_{c t 1} \varepsilon_{c t} d \varepsilon_{c t} .
\end{gathered}
$$

Для низхідної вітки розтягнутої зони перерізу, до моменту досягнення в крайніх розтягнутих волокнах деформацій, що рівні $\varepsilon_{c(1)}=\varepsilon_{c t, l}=0,00025$, зусилля $N_{t 2}=0$. При $\varepsilon_{c(1)}>\varepsilon_{c t, l}=0,00025$ внутрішні зусилля визначаються:

$$
\begin{gathered}
N_{t 2(1)}=b \int_{h-x_{(1)}-x_{t 2}}^{x_{t 2}} \sigma_{c t 2} d x_{t}=b \frac{x_{t 2}}{\varepsilon_{c t(1)}-\varepsilon_{c t, 1}} \int_{\varepsilon_{c t, 1}}^{\left.\varepsilon_{c t t} 1\right)} \sigma_{c t 2} d \varepsilon_{c t}, \\
M_{t 2(1)}=b \int_{h-x_{(1)}-x_{t 2}}^{x_{t 2}} \sigma_{c t 2} x_{t} d x_{t}=b\left(\frac{x_{t 2}}{\varepsilon_{c t(1)}-\varepsilon_{c t, 1}}\right)^{\varepsilon_{c t(1)}} \int_{\varepsilon_{c t, 1}}^{\sigma_{c t 2} \varepsilon_{c t}} d \varepsilon_{c t},
\end{gathered}
$$

де згідно гіпотези плоских перерізів:

$$
d x_{t}=\frac{x_{t 2}}{\varepsilon_{c t(1)}-\varepsilon_{c t, 1}} d \varepsilon_{c t},
$$

де $x_{t 2}$ - висота розтягнутої зони в межах низхідної вітки.

У формулах (8), (11), (14-17) у підінтегральні вирази входять напруження в бетоні $\sigma_{c}, \sigma_{c t 1}, \sigma_{c t 2}$, що описуються залежностями (1-3). Значення $N_{c}$ після підстановки (1) у вираз (8) із подальшим інтегрування набуває наступного вигляду:

$$
N_{c(1)}=f_{c d} b x_{(1)} \sum_{k=1}^{5} \frac{a_{k}}{k+1}\left(\frac{\varepsilon_{c(1)}}{\varepsilon_{c 1}}\right)^{k} .
$$

Момент для стиснутої зони бетону відповідно визначається: 


$$
M_{c(1)}=f_{c d} b x_{(1)}^{2} \sum_{k=1}^{5} \frac{a_{k}}{k+2}\left(\frac{\varepsilon_{c(1)}}{\varepsilon_{c 1}}\right)^{k} .
$$

Для розтягнутої зони на висхідній вітці, при $\varepsilon_{c(1)} \leq \varepsilon_{c t, l}=0,00025$, у результаті підстановки виразу (2) та інтегрування, зусилля відповідатимуть:

$$
\begin{aligned}
& N_{t 1(1)}=f_{c t d} b\left(h-x_{(1)}\right) \sum_{k=1}^{5} \frac{a_{k}}{k+1}\left(\frac{\varepsilon_{c t(1)}}{\varepsilon_{c t, 1}}\right)^{k} ; \\
& M_{t 1(1)}=f_{c t d} b\left(h-x_{(1)}\right)^{2} \sum_{k=1}^{5} \frac{a_{k}}{k+2}\left(\frac{\varepsilon_{c t(1)}}{\varepsilon_{c t, 1}}\right)^{k} .
\end{aligned}
$$

При досягненні в крайніх розтягнутих волокнах деформацій рівних $\varepsilon_{c(1)}>\varepsilon_{c t, l}=0,00025$, зусилля в розтягнутій зоні в межах дії висхідної вітки визначаються за формулами:

$$
\begin{aligned}
& N_{t 1(1)}=f_{c t d} b\left(h-x_{(1)}-x_{t 2}\right) \sum_{k=1}^{5} \frac{a_{k}}{k+1} \\
& M_{t 1(1)}=f_{c t d} b\left(h-x_{(1)}-x_{t 2}\right)^{2} \sum_{k=1}^{5} \frac{a_{k}}{k+2} .
\end{aligned}
$$

Для низхідної вітки розтягнутої зони перерізу, в результаті підстановки виразу (3) та інтегрування, зусилля визначатимуться:

$$
\begin{aligned}
& N_{t 2(1)}=f_{c t d} b \frac{x_{t 2}\left(1,0075\left(\varepsilon_{c t(1)}-\varepsilon_{c t, 1}\right)-15,15\left(\varepsilon_{c t(1)}{ }^{2}-\varepsilon_{c t, 1}^{2}\right)\right)}{\varepsilon_{c t(1)}-\varepsilon_{c t, 1}} \\
& M_{t 2(1)}=f_{c t d} b \frac{x_{t 2}{ }^{2}\left(0,50375\left(\varepsilon_{c t(1)}{ }^{2}-\varepsilon_{c t, 1}{ }^{2}\right)-10,1\left(\varepsilon_{c t(1)}{ }^{3}-\varepsilon_{c t, 1}{ }^{3}\right)\right)}{\left(\varepsilon_{c t(1)}-\varepsilon_{c t, 1}\right)^{2}}
\end{aligned}
$$

Значення висоти розтягнутої зони перерізу для низхідної вітки $-x_{t 2}$, можна визначити використовуючи подібність трикутників, згідно епюри деформацій (рис. 2):

$$
x_{t 2}=\frac{h\left(\varepsilon_{c t(1)}-\varepsilon_{c t, 1}\right)}{\varepsilon_{c(1)}+\varepsilon_{c t(1)}} .
$$

Підставивши (27) у вирази (25) і (26) отримаємо:

$$
N_{t 2(1)}=f_{c t d} b \frac{h\left(1,0075\left(\varepsilon_{c t(1)}-\varepsilon_{c t, 1}\right)-15,15\left(\varepsilon_{c t(1)}{ }^{2}-\varepsilon_{c t, 1}^{2}\right)\right)}{\varepsilon_{c(1)}+\varepsilon_{c t(1)}} \text {; }
$$




$$
M_{t 2(1)}=f_{c t d} b \frac{h^{2}\left(0.50375\left(\varepsilon_{c t(1)}{ }^{2}-\varepsilon_{c t, 1}^{2}\right)-10,1\left(\varepsilon_{c t(1)}{ }^{3}-\varepsilon_{c t, 1}^{3}\right)\right)}{\left(\varepsilon_{c(1)}+\varepsilon_{c t(1)}\right)^{2}} .
$$

Формули (12), (13), (19-29) можна використовувати для визначення напружено-деформованого стану нормальних перерізів комбінованоармованих згинальних елементів на будь-якій стадії навантаження та їх несучої здатності. При визначенні несучої здатності, за критерії ii вичерпання приймаються значення максимальних і граничних деформацій сталефібробетону та арматури. Задачі вирішуються методом послідовних наближень, підбираючи значення $\varepsilon_{c(1)}$ і значення $x_{(1)}$ таким чином, щоб задовольнялися рівняння рівноваги (4) i (5).

Для оцінки ефективності методики було виконано експериментальні дослідження нерозрізних комбіновано-армованих сталефібробетонних балок. Методика дослідження та характер роботи балок у процесі випробувань описані в роботах [7, 9]. Також виконаємо для порівняння розрахунки за методикою, що наведена в ДСТУ -Н Б В.2.6 - 218:2016 [1].

Для застосування наведених методик використовуємо експериментально встановлені механічні характеристики матеріалів для балок другої серії (2Б1-1 і 2Б1-2): міцність сталефібробетону на стиск $f_{c k}=24,5 \mathrm{MПа;}$ міцність на розтяг $f_{c t}=2,35$ MПа $\varepsilon_{c l}=180,6 \times 10^{-5}$. Значення $a_{i}$ визначалися згідно методики НДІБК і відповідно становили: $a_{1}=2,534 ; a_{2}=-2,226$; $a_{3}=0,865 ; \quad a_{4}=-0,189 ; \quad a_{5}=0,016$. Розміри перерізу $b \times h=10 \times 16$ см. Армування для балок 2Б1-1,2 приймаємо двома стержнями Ø10А500С, для балок 2Б1-3 - двома стержнями Ø12А500С. Характеристики арматури: $E_{s}=195000 \mathrm{M \Pi a} ; \sigma_{y}=508 \mathrm{M \Pi а;} \varepsilon_{s 0}=0,00314$.

За результатами розрахунку побудовано графік залежності «згинальний момент - кривизна», піковій точці якого відповідає величина руйнуючого згинального моменту - представлено на рис. 3 .

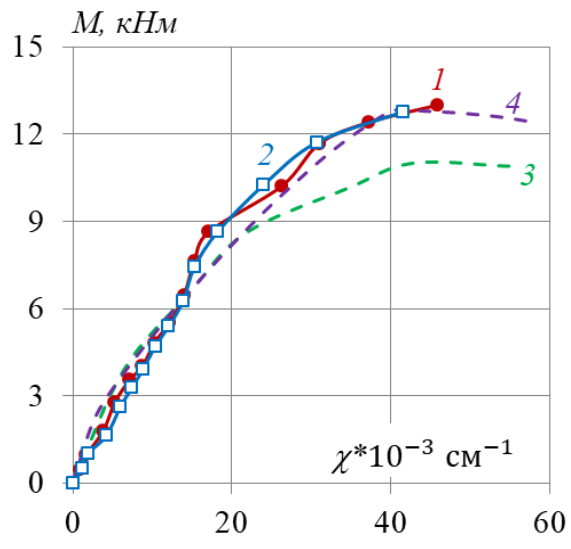

Рис. 3. Діаграма «моменткривизна» для балок 2Б1:

1 - експериментальні дані для балки 2Б1-1;

2 - експериментальні дані для балки 2Б1-2;

3 - теоретичні дані отримані за допомогою ДСТУ -Н Б В.2.6 218: 2016 ;

4 - теоретичні дані за запропонованою деформаційною методикою 
Таблиця 1

Порівняння результатів розрахунку несучої здатності балок

\begin{tabular}{|c|c|c|c|c|c|}
\hline $\begin{array}{l}\text { Марка } \\
\text { зразка }\end{array}$ & $\begin{array}{l}\mathrm{M}_{u}^{\exp }, \\
\mathrm{\kappa H} \mathrm{H}^{*}\end{array}$ & $\begin{array}{c}\mathrm{M}_{u}{ }^{\prime}, \\
\kappa \mathrm{H}^{*} \mathrm{M}\end{array}$ & $\begin{array}{c}\mathrm{M}_{u}^{2} \\
\mathrm{\kappa} \mathrm{H}^{*} \mathrm{M}\end{array}$ & $\begin{array}{l}\mathrm{M}_{u}^{I} \cdot / \\
\mathrm{M}_{u}^{\text {exp }}\end{array}$ & $\begin{array}{l}\mathrm{M}_{u}^{2 \cdot} \cdot 1 \\
\mathrm{M}_{u}^{\exp }\end{array}$ \\
\hline $2 Б 1-1$ & 13,0 & \multirow{2}{*}{10,9} & \multirow{2}{*}{12,83} & 0,84 & 0,98 \\
\hline 2 Б1-2 & 12,77 & & & 0,85 & 1,004 \\
\hline \multicolumn{6}{|c|}{$\begin{array}{l}\mathrm{M}_{u}{ }^{e x p} \text { - експериментальні дані; } \\
\mathrm{M}_{u}{ }^{1} \text { - руйнівне значення моменту за ДСТУ -Н Б В.2.6 - 218:2016; } \\
\mathrm{M}_{u}{ }^{2} \text { - руйнівне значення моменту за запропонованою методикою. }\end{array}$} \\
\hline
\end{tabular}

Характерною особливістю методики розрахунку сталефібробетонних елементів, згідно з ДСТУ-Н Б В.2.6 - 218:2016 [1] є те, що розрахунковий опір фібробетону на стиск приймається рівним розрахунковому опору бетону матриці, який використовується для його отримання. Для дрібнозернистого бетону, міцність матриці на стиск зазвичай значно менша, ніж сталефібробетону, що суттєво впливає на несучу здатність перерізу

\section{Висновки.}

На основі отриманих результатів при визначенні характеристик напружено-деформованого стану, запропонована деформаційна методика із врахуванням повних діаграм деформування бетону при стиску і розтягу показує кращу збіжність порівняно із методикою ДСТУ. Середнє відношення теоретичних руйнівних згинальних моментів до експериментальних згідно методики за ДСТУ [1] становить $k_{m}=0,843$, а згідно запропонованої деформаційної методики - становить $k_{m}=0,98$.

\section{References}

1. DSTU-N B B.2.6-218: 2016. Nastanova z proektuvannia ta vyhotovlennia konstruktsii iz dyspersno-armovanoho betonu. [Chynnyi vid 2017-04-01]. Kyiv, 2017. 32 s. (Derzhavnyi standart Ukrainy).

2. DSTU B B.2.6.-156: 2010. Betonni ta zalizobetonni konstruktsii $\mathrm{z}$ vazhkoho betonu. Pravyla proektuvannia. [Chynnyi vid 2011-06-01]. Kyiv, 2011. 123 s. (Derzhavnyi standart Ukrainy).

3. M.C. Nataraja, N. Dhang, A.P. Gupta. Stress-strain curves for steel-fiber reinforced concrete under compression. Cement and Concrete Composites. 1999. Vol. 21. Issues 5-6, pp. 383-390.

4. Kinash R., Bilozir M. Deformational calculation method of bearing capability of fiber-concrete steel bending elements. Technical Transactions: Architecture. 2014. I. 8-A (15), № 111. P. 49-58.

5. Bilozir V. V. Vplyv nyzkhidnoi vitky diahramy deformuvannia stalefibrobetonu za roztiahu na nesuchu zdatnist balok. Visnyk Lvivskoho natsionalnoho ahrarnoho universytetu: arkhitektura i silskohospodarske budivnytstvo. 2015. № 16. S. 60-64. 
6. RILEM TC 162-TDF. "Design of steel fibre reinforced concrete using the $\sigma-\mathrm{w}$ method - principles and applications (Chairlady L. Vandewalle)." Materials and Structures, Vol. 35, 2002, pp. 262-278.

7. Ninichuk M. V. Vplyv sposobu armuvannia stalevymy fibramy nerozriznykh zalizobetonnykh balok na yikh napruzheno deformovanyi stan. Resursoekonomni materialy, konstruktsii, budivli ta sporudy. 2015. Vyp. 31. S. 460-467.

8. Bambura A. M. Analitychne opysannia diahramy mekhanichnoho stanu armatury dlia zalizobetonnykh konstruktsii. Budivelni konstruktsii: Mizhvidomchyi naukovotekhnichnyi zbirnyk. Kyiv : NDIBK, 2003. Vyp 59. Knyha 1. S. 131-136.

9. Babych Y. M., Andriichuk O. V., Kysliuk D. Y, Savitskiy V. V., Ninichuk M.V. Results of experimental research of deformability and crack-resistance of two span continuous reinforced concrete beams with combined reinforcement. IOP Coference Series: Materials Science and Engineering. 2019. Vol. 708. 012043. DOI: 10.1088/1757899X/708/1/012043.

\section{Список використаної літератури}

1. ДСТУ-Н Б В.2.6-218:2016. Настанова 3 проектування та виготовлення конструкцій із дисперсно-армованого бетону. [Чинний від 2017-04-01]. Київ, 2017. 32 с. (Державний стандарт України).

2. ДСТУ Б В.2.6.-156:2010. Бетонні та залізобетонні конструкції з важкого бетону. Правила проектування. [Чинний від 2011-06-01]. Київ, 2011. - с. 123. (Державний стандарт України).

3. M.C. Nataraja, N. Dhang, A.P. Gupta. Stress-strain curves for steel-fiber reinforced concrete under compression. Cement and Concrete Composites. 1999. Vol. 21. Issues 5-6, pp. 383-390.

4. Kinash R., Bilozir M. Deformational calculation method of bearing capability of fiber-concrete steel bending elements. Technical Transactions: Architecture. 2014. I. 8-A (15), № 111. P. 49-58.

5. Білозір В. В. Вплив низхідної вітки діаграми деформування сталефібробетону за розтягу на несучу здатність балок. Вісник Львівського національного аграрного університету: архітектура $i$ сільськогосподарське будівниитво. 2015. № 16. С. 60-64.

6. RILEM TC 162-TDF. "Design of steel fibre reinforced concrete using the $\sigma-\mathrm{W}$ method - principles and applications (Chairlady L. Vandewalle)." Materials and Structures, Vol. 35, 2002, pp. 262-278.

7. Нінічук М. В. Вплив способу армування сталевими фібрами нерозрізних залізобетонних балок на їх напружено деформований стан. Ресурсоекономні матеріали, конструкції, будівлі та споруди. 2015. Вип. 31. С. 460-467.

8. Бамбура А. М. Аналітичне описання діаграми механічного стану арматури для залізобетонних конструкцій. Будівельні конструкиї̈: Міжвідомчий науковотехнічний збірник. Київ : НДІБК, 2003. Вип 59. Книга 1. С. 131-136.

9. Babych Y. M., $\quad$ Andriichuk O. V. , Kysliuk D. Y, $\quad$ Savitskiy V. V., Ninichuk M.V. Results of experimental research of deformability and crack-resistance of two span continuous reinforced concrete beams with combined reinforcement. IOP Conference Series: Materials Science and Engineering. 2019. Vol. 708. 012043. DOI: 10.1088/1757-899X/708/1/012043. 